\title{
LA FORMACIÓN DE MILICIAS GENERALES EN LOS REINOS DE LA CORONA DE ARAGÓN DURANTE EL REINADO DE CARLOS II, 1665-1700
}

\author{
ANTONIO ESPINO LÓPEZ \\ Universidad de Barcelona
}

Señalaba

\section{Resumen}

En este trabajo trato cómo durante el reinado de Carlos II la Monarquía Hispánica intentó que, además del servicio de armas habitual (levas y reclutas de tercios), los reinos de la Corona de Aragón levantasen Milicias Generales a la manera de Castilla, pero teniendo en cuenta que su condición de reinos forales obligará a la Monarquía a pactar dicho servicio.

\section{Palabras Clave}

Monarquía Hispánica, Siglo XVII, Milicia General, Servicio de Tropas.

\begin{abstract}
In this article,the author intends to do an analysis about how during Charles II's reign, the royal staff tryed to conscript the Crown of Aragon of adding to its own usual service of arms (consisting on levy troops and recruiting the soldiers so called "tercios"), a General Militia in the Castilian shape, althrough considering that its own condition of foral kingdom obbliged the Monarchy to pact with the Crown of Aragon the aforesaid service.
\end{abstract}

\section{Key words}

Spanish Monarchy, XVIIth century, General Militia, service on troops. 
Señalaba I.A.A. Thompson hace algunos años que los sistemáticos intentos de organizar una milicia general en Castilla $(1552,1562,1565,1570,1588$, $1596,1598,1609,1625)$ fueron "una medida legítima y sensata de defensa nacional cuyos objetivos eran formalizar las acostumbradas obligaciones de las ciudades de ayudar a su propia defensa y dotar a estas fuerzas locales de algún tipo de organización permanente"1. Con semejante disposición la Monarquía conseguía un doble objetivo: en primer lugar mejorar la defensa; pero también disponer de una masa de hombres susceptibles de ser reclutados, dotados de un cierto entrenamiento, con el armamento correspondiente -un asunto siempre arduo- y encuadrados por unos mandos que, hasta cierto punto, podían ser controlados por la Corona ${ }^{2}$.

Las urgencias militares durante el reinado de Felipe IV reiterarían la necesidad de contar con tropas de reserva susceptibles de ser empleadas en la defensa de los territorios; una situación quizá aún más evidente en el de su sucesor. Uno de nuestros mejores especialistas en esta temática, José Contreras, ha hablado del "cambio histórico del predominio del reclutamiento centralizado y voluntario a un sistema más descentralizado, diversificado y amplio...", cuyo resultado fue que se pasó a "un modelo de ejército-milicia más híbrido, basado en la combinación de tropas veteranas permanentes y de milicias-ocasionales". "La plasmación concreta de esta nueva filosofía militar dio como resultado histórico la formación de los llamados Tercios Provinciales (paradigma máximo de la tendencia hacia la provincialización), que se proyectaron, levantaron e institucionalizaron definitivamente entre 1637 y $1663 . . . " 3$.

El siguiente paso fue desarrollar la idea de un plan general de milicias, tal y como se efectuó a finales del siglo XVII. Según el conde de Clonard, en 1692 se hizo un alistamiento de toda la milicia disponible de Castilla, siendo su número 465.305 personas, pero faltaban armas para todos -un problema común a todos los territorios y que venía de lejos-; por un decreto del 20 de enero de 1694, se dictaminó la creación de diez tercios nuevos de entre 1.000 y 1.300

\footnotetext{
${ }^{1}$ I.A.A. Thompson, Guerra y decadencia. Gobierno y administración en la España de los Austrias, 1560-1620, Barcelona, 1981, pp. 156-161.

${ }^{2}$ Véase al respecto, mi trabajo, "La sociedad catalana y la posesión de armas en la Época Moderna, 1501-1652", Revista de Historia Moderna, $\mathrm{n}^{\circ}$ 21, Universidad de Alicante, Alicante, 2003, pp. 447-472.

${ }^{3}$ J. CONTRERAS, "La reorganización militar en la Época de la decadencia española (1640-1700)", en Millars, Universitat Jaume I, Castellón, n ${ }^{\circ}$ XXVI, 2003, pp. 132-134; y "El siglo XVII y su importancia en el cambio de los sistemas de reclutamiento durante el Antiguo Régimen", en Studia Historica. Historia Moderna, Salamanca, no 14, 1996, p. 154.
} 
hombres debido a la falta de tropas hispanas en los ejércitos de Flandes, Milán y Cataluña. La orden era de reparto de dos soldados por cada cien vecinos, de entre veinte y cincuenta años, con algunas exenciones, pero sin decidirse a que fuera un reparto universal: en primer lugar se debía enrolar a los vagabundos, sediciosos y demás "desechos" sociales, seguidos por quienes menos falta hiciesen en los pueblos... Sólo en último extremo se enrolaban los voluntarios ${ }^{4}$.

Por su parte, la propuesta del autor, anónimo, de un Discurso sobre el tiempo presente. Año de $1694^{5}$ iba un poco más allá al demandar la obligación de los parientes -"fiadores"- de un soldado a pagar un sustituto en caso de muerte o deserción del mismo, de este modo se aseguraba que el ejército mantendría el nivel de tropas en campaña. Ello implicaba que la tropa no podía surgir de los sectores más desestructurados, puesto que la virtud del plan estaba, precisamente, en que era la familia la encargada de enviar sustitutos en caso de necesidad y no el rey, como era lo usual:

"Ya está visto, y conocido, la poca asistencia de los soldados en el ejército que se levantan y las descomposturas que la Monarquía padece por esta falta. Supuesto esto, forzoso será buscar forma y modo para que no se descaminen y estén siempre asistentes aquellos que se destinen al servicio del rey, haciendo de esta ocupación oficio perpétuo... A quien esta comisión se encargare, deberá asistir en la ciudad del reino o cabeza de partido a que fuere destinado y conforme el orden que tuviere de la gente que ha de hacer para formar el tercio, la repartirá por la ciudad y por todos los lugares y villas del partido, acomodando a todos y a cada uno en particular la que fuere capaz de dar, mandando a la ciudad donde estuviere le entreguen la lista de todos los vecinos que hubiere en ella, cuántos hijos cada uno tiene y la edad, mandando venir delante de sí a dichos vecinos con todos los hijos que tuvieren y conforme la $\mathrm{c}<\mathrm{u}>$ antidad $\mathrm{y}$ edad suficiente para el ministerio de

${ }^{4}$ Conde de Clonard, Historia orgánica de las armas de infantería y caballería españolas, desde la creación del ejército permanente hasta el día, Madrid, 1854. Tomo V, pp. 13-23 y 26 y ss.

${ }^{5}$ Biblioteca Nacional (Madrid), Ms. no 11.023. Véase mi artículo "El problema de la escasez de tropas durante la Guerra de los Nueve Años, 1689-1697. El 'Discurso sobre el tiempo presente. Año de 1694', Revista de Historia Militar, nº 82, Madrid, 1997, pp. 73-100. 
soldados. Les quitará aquellos que fuese lícito, atendiendo a la necesidad que los padres y viudas tuvieren de ellos, y la vida extravagante que hubieren ejercido, haciendo asentarles plaza. Y que sus padres, hermanos, cuñados o parientes más llegados quedasen por fiadores y obligados a los gastos que hiciere cada uno hasta que llegue el ejército, para que, en caso que el tal soldado huyere, pueda hacer ponerles otro en su lugar. Dirá en el asiento de cada uno fulano, hijo de fulano, natural de tal lugar, de tanta edad, declarando la estatura del cuerpo, color del rostro y cabello, con las más señales que tuviere exteriores, su fiador fulano, por la farda de este quedó obligado dar hasta que llegue a dicho ejército. Esto sirve para que cuando se pasa muestra, si algunos hubieran huido, los capitanes no pasen a otros por ellos, costumbre tan antigua como usada en los ejércitos y mucho más en los de España, que ha causado muchos males sucesos. Los pendulistas, a cuyo cargo estuviese el pasar dicha muestra, tienen obligación de atender bien a cada soldado cuando la pasa, si tiene todas las señales, el lugar, padre y fiador, conforme estuvieren referidas en el asiento de cada uno. Si alguno huyere, estará obligado dicho fiador a pagar toda la costa, desde el día en que sentó plaza el soldado hasta que llegó a sentarla en dicho ejército en la Contaduría y Veeduría General. Si muriere el soldado en el servicio del rey, quedará desobligado el fiador de lo dicho.

En los partidos donde se levantaren los tercios quedará en cada uno de ellos una lista de todos los que han sentado plaza a la persona que Su Majestad quisiera encomendar esta función, para que por ella haga la recondu[c]ción de los soldados huidos que se le avisare, y ver si viene cierta con la que se quedó. Cada Maestre de Campo ha de llevar también la de su tercio, para que por ella asiente a sus soldados en los libros de la Contaduría y Veeduría General, y estará obligado a enviar todos los años a su partido todas las nóminas sacadas por los oficiales de dicha Contaduría y Veeduría General, firmadas del cabo que gobernare el ejército, de todos los soldados que hubieren huido y muerto en servicio del rey a la persona que tuviere dada $\mathrm{Su}$ Majestad esta comisión, que la tal obligará a los fiadores a que paguen la costa que el soldado huido hubiera hecho, o entregando el mismo o que se aliste otro con las mismas 
referidas circunstancias. Y si el padre del hijo huido tuviere otro, hacerle sentar plaza, quedando siempre fiador, y si alguno de estos no tuviere con qué pagar el gasto hecho por el soldado huido, vaya el fiador por él, aunque sea casado. Los que se hubieren muerto en la guerra, hacerlos por cuenta de $\mathrm{Su}$ Majestad y hecha la reconducción así de los huidos por cuenta de los fiadores, como la de los muertos por la del rey, remitirlos con los sargentos que el Maestre de Campo enviará de cada compañía para que el número de cada una esté completo.

Pero para que entren seguros los soldados en el ejército y se libre a los fiadores cuanto sea posible de ser maltratados por ellos, queriendo Su Majestad, podrá mandar orden a todas las justicias y alcaldes del reino para que cualquier $<a>$ soldado que cogieren no trayendo licencia de su capitán, firmada por el cabo mayor, y registrada por la Contaduría y Veeduría General, le pueda ahorcar la justicia de cualquiera lugar o aldea, con la pena de procederse contra dichos jueces si faltaren al orden, que con un ejemplar de esto será cierta la asistencia de todos".

Por otro lado, se debería combinar la recluta de estos nuevos tercios con otros de reserva, que serían unas milicias defensivas utilizables en caso de apuro:

"Haciéndose, pues, un ejército formado con el orden que aquí se apunta, conviene mucho a Su Majestad mandar levantar tercios de socorro en cada reino o cabezas de partido, para que estén siempre prevenidos a marchar todas las veces que les fuere mandado, repartiendo como se ha dicho en cada reino un tercio, y pueden componerse estos de hombres que no sean precisamente menesterosos a los pueblos y lugares donde se levantaren, sino que se hagan de los que viven más ejercitados en la ociosidad que en el trabajo, y aunque sean casados, viviendo con alguna desenvoltura en las costumbres. Estos tales no necesitan de fianza, ni de las circunstancias ya apuntadas, que para los soldados asistentes en el ejército se requieren, sino que estén en sus casas y tierras, para que habiendo necesidad de ellos, estén pronto para cualquiera aviso poder ponerse en marcha, porque como los socorros que se hacen en España son siempre con tanta dilación, peligra el que nunca llegan a tiempo 
y estando éstos ya dispuestos para ello, llegarán sin hacer falta, que es lo que intentamos".

Sin duda, en los territorios forales, como los de la Corona de Aragón, la realidad de una milicia general debía ser especialmente interesante para la Monarquía, pero, precisamente por su condición de reinos forales, su instauración no podía seguir los mismos cauces que en Castilla. Había que pactar cualquier servicio, si bien las necesidades de la guerra obligaban, por encima de cualquier otra consideración, a los reinos periféricos a mostrarse receptivos ante la necesidad de ejercer su derecho, además de su obligación, a la defensa. Un derecho que pasaba, como veremos, por el reparto de armas ${ }^{6}$.

\section{CATALUÑ̃}

Durante el reinado de Carlos II, además de los tercios pagados por el Consell de Cent de la ciudad de Barcelona y la Generalitat, los diversos virreyes siempre buscaron obtener de Cataluña nuevas fuerzas que pudieran encuadrarse de alguna forma en el Ejército Real. Según N. Feliu de la Peña, para las operaciones de 1673-1674, el virrey San Germán intentó que las veguerías pagasen 4.000 hombres integrados en nueve tercios para ayudarle en la hipotética reconquista del Rosellón. Pero, a la hora de la verdad, Cataluña sólo pagó 1.800 hombres y, lo peor de todo, al fallar toda la operación, con el fracaso de la Conspiración de Vilafranca del Conflent, en dos días desertaron 5007. En 1677 y 1678, el servicio de las veguerías terminó reduciéndose a dos tercios mal pagados, puesto que el donativo que había que realizar para costearlos aún no se había cobrado en $1679^{8}$.

El proyecto más importante, a nuestro juicio, para levantar un tercio en Cataluña pagado por los comunes del Principado data de 1689. El autor, anónimo, pero con toda probabilidad miembro de la Real Audiencia de Cataluña, defendía la creación de una agrupación de 1.000 hombres, pagada a perpetuidad por el Principado -aunque si invernaban se les reduciría la paga a la mitad o a una tercera parte- y reclutada a razón de un hombre por cada veinte fuegos. La

\footnotetext{
${ }^{6}$ A. Espino, "La sociedad catalana y la posesión de armas en la Época Moderna, 1501-1652", Revista de Historia Moderna, n 21, Universidad de Alicante, Alicante, 2003, pp. 447-472.

${ }^{7}$ N. Feliu de la PeÑa, Anales de Cataluña, Barcelona, 1709, Vol. III, p. 359. ACA, CA, Leg. 432, virrey San Germán a la regente, 7-IV-1674.

${ }^{8}$ ACA, CA, Leg. 330, consulta del consejo, 23-II-1679.
} 
entrada sería de cinco libras y media, dando el virrey el pan de munición y las armas. El principal problema era sacar a suertes los reclutas, por ello el autor proponía "usar muy en secreto, y si fuera lícito juramentados, de otros medios y cautela prudente, y poco injusto, para hacer salir en suerte los hombres que le tocase de aquellos solos moços más ociosos y inquietos, y en su defecto los menos perjudiciales a sus casas...". En cualquier caso, se advertía que el dinero obtenido se debería gastar exclusivamente en este servicio, "por [h] aberse otras veces el dinero divertido a otros fines que los propuestos" ${ }^{\prime \prime}$. El plan se aplicaría con muchas variantes a partir de 1695 .

En febrero de 1695, el virrey Gastañaga informaba a Carlos II de un madurado plan para levar en Cataluña 2.500 hombres en forma de milicias, que serían adscritas a dos tercios de nueva creación, de 1.000 hombres cada uno, y cinco compañías de cien hombres a incorporar a cualquier otro tercio. Una recomendación inicial era reducir dispendios en base a "la moderación de los excesivos gastos que se han hecho otras veces en las entradas...", ya fuese por falta de tiempo u otro motivo, de modo que pedía una cuota de enganche de tres libras y dos reales de ardites al día de estipendio, más el uniforme, "que no es pequeño cebo una golosina tan lucrosa". Días más tarde, la Generalitat contestó algunas de las características de este servicio, llegando a un acuerdo con el virrey. Este se conformó con una leva de 2.000 hombres de buena calidad dirigida por los diputats. La propia Generalitat elegiría la plana mayor de la oficialidad, que a su vez nombraría a los oficiales menores. El virrey Gastañaga se comprometía a acoger en el Ejército Real a toda la oficialidad al licenciar los tercios siempre y cuando aquellos fueran gente de calidad y con experiencia de mando. La advertencia final de Gastañaga nos recuerda las peculiaridades del gobierno de Cataluña: "Alguno (con poco conocimiento de la subsistencia desta provincia, de sus privilegios y del genio natural de sus [h]abitantes) puede ser que con celo indiscreto, o sedicioso, haia pensado en que por lo mismo que este Principado está bien dispuesto para todo lo que fuera del servicio de Vuestra Majestad que pudieren conceder, se le debiere mandar que conmutase el gasto de estas levas en vestir, remontar y pagar algunos cuerpos del exército, cotejando la quenta del importe, para tasarlos a una contribución fija, aunque esta sea accidental, por esta presente campaña, y aunque pudiera ser mejor establecido, sería tan malo aún para propuesto, ni imaginado, que desconcertaría (si se dijese) toda la armonía política y racional del afecto, firmeza y ternura con que este Principado ama, sirve y servirá a Vuestra Majestad mejor con la suavidad de sus

${ }^{9}$ BN, Ms. 2.399, "Proyecto para levantar un tercio de 1000 hombres...", dirigido al virrey por el virrey Villahermosa, 3-VII-1689. 
Reales Insinuaciones que persuaden más estos genios que con las severas ordenes de precisión absoluta"10.

Pero la realidad fue muy diferente, y el servicio de 2.500 hombres se transformó en dos tercios que, en abril de 1695, constaban de 673 y 925 hombres, respectivamente. No se buscó el incremento de estas tropas, sino conservarlas.

\section{VALENCIA}

En el caso del reino de Valencia, las Cortes de 1645 fueron muy definitivas para todo lo relacionado con el encuadramiento de tropas en el Reino; por un lado, porque los brazos del Reino no dudaron en votar un servicio económico con el que subvencionar una fuerza militar compuesta por 1.200 hombres por seis campañas; y, lo más importante, porque los brazos, en lugar de introducir nuevos impuestos para subvencionar dicho servicio, como se había hecho hasta las Cortes de 1626, decidieron "repartir los soldados proporcionalmente entre los lugares del País, de manera que 'cada poble havia de trametre una quota del seus habitants a la guerra i cercar els diners per a pagar-los, segons un repartiment que havia de fer una junta representativa del Regne sancer ' o Junta de Leva integrada por electos de los tres estamentos y en la que los jurados, racional y síndico de la capital (...) tenían un peso decisivo". En la práctica, la formación de dicha Junta significó que desde 1645 la Monarquía ya no necesitó convocar Cortes en Valencia para pedir tropas y dinero para la guerra, sino que se limitará a demandar a dicha Junta que realizase un nuevo servicio ${ }^{11}$. Pero también que se estaba utilizando un mecanismo susceptible de ser aprovechado para convocar sucesivos repartos de tropas en forma de milicia.

En realidad, hasta el bombardeo de Alicante de 1691 no hubo necesidad de reorganizar de forma clara la milicia para la defensa efectiva del Reino. Según S. García Martínez, la idea primigenia fue del marqués de Denia cuando ejerció como virrey de Valencia en las postrimerías del reinado de Felipe II; a fines de 1597 se aprobaba la creación de una fuerza de 10.000 hombres destinada tanto a prevenir los ataques del exterior, como a defenderse de cualquier posible

\footnotetext{
${ }^{10}$ ACA, CA, Leg. 468, Gastañaga a Carlos II, 5-II-1696.

${ }^{11}$ Véanse, S. García MartíneZ, Valencia bajo Carlos II, Villena, 1991, pp. 283 y ss. y M. VILA,"La aportación valenciana a la guerra con Francia (1635-1640)", en Estudis, No 8, 19791980, pp. 125-142.
} 
amenaza de los moriscos. En 1628-1629, una nueva pragmática, ahora de Felipe IV, reducía a ocho mil el volumen total de efectivos. Pero cuando se produjeron algunas incursiones franco-catalanas en el norte del Reino, realizadas desde la conquista de Tortosa (1650), la milicia fue sustituida por una serie de tercios de socorro, compuestos por 5.000 infantes, para la defensa de la frontera. Poco antes de su muerte, Felipe IV ordenó constituir un nuevo batallón de milicia efectiva compuesto por seis mil infantes, 2.400 correspondían a la parte de Levante y 3.600 a la de Poniente del Reino, exceptuando, como se había hecho siempre, los lugares marítimos -una treintena- que iban de Vinaroz a Guardamar y cuyos efectivos debían mantenerse para defenderlos, así como la propia ciudad de Valencia, defendida por sus gremios. Este fue el modelo de batallón que resultó ineficaz para la defensa de Alicante ${ }^{12}$. La reacción fue rápida: ante la constatación de que "...las armas enemigas de Su Majestad... infestan por todas partes las fronteras y Reynos de su Real Corona, y la falta de medios con que se hallan los reales cofres para asistir con levas de soldados voluntarios a tantas provincias, como es necesario guarnecer, y que los batallones de las milicias efectivas de infantería y caballería que para suplir la referida falta en este presente reyno de Valencia se han formado en diferentes ocasiones se hallan sin disposición de poder acudir a las ocasiones impensadas, de las que pueden ofrecerse cada día, por no haberse acabado de formar con la perfección que se requiere, como se experimentó en la invasión que el año pasado hizo la Armada de Francia... después de haber premeditado la materia..., deliberamos que se suprimieran y extinguieran todos los batallones de infantería y caballería que había formados con nombre de milicia efectiva de la defensa y custodia del Reyno, y se formaran otros de nuevo, dando providencia en todas las cosas y cabos de que se necesita, según la ocurrencia de los tiempos, para que se mantengan con buen orden, disposición y disciplina militar, de suerte que de su asistencia y auxilio se pueda confiar la defensa de este reyno en todas las ocasiones...". Carlos II aprobó el 26 de marzo de 1692 la formación de este nuevo modelo de milicia efectiva según el plan que le envió el virrey Castel Rodrigo justo un mes antes ${ }^{13}$; la Real Pragmática creando este nuevo batallón se imprimió con fecha 28 de abril de 1692 y constaba de 6.000 soldados de infantería y 1.300 de caballería a repartir entre los habitantes del Reino. En su carta, Carlos II insistía, parafraseando a su virrey, en que ante un peligro como el vivido en julio del año anterior, en la milicia valenciana "...ni los maestres de campo sabían de sus tercios, ni los capitanes de sus soldados, sin que ninguna de

\footnotetext{
${ }^{12}$ S. García Martínez, Valencia bajo Carlos II, Villena, 1991, pp. 288-291.

${ }^{13}$ ACA, CA, Leg. 559/43, virrey Castel Rodrigo a Carlos II, 26-II-1692.
} 
las pragmáticas pertenecientes a la formación de la milicia efectiva publicadas por muchos de vuestros antecesores... estuviera en observancia, ni pudiera tenerla...". Dicho batallón se iba a formar exceptuando la milicia de la propia ciudad de Valencia y la de los lugares vecinos a la costa, los cuales tendrían, por razones obvias, que acudir en bloque a su defensa, como ya hemos visto que se había hecho siempre. La idea era formar ocho tercios, tres en la parte de Levante (Segorbe, Castellón, San Mateo) y cinco en la de Poniente (Alcira, Játiva, Alcoy, Onteniente, Orihuela), compuesto cada uno de diez compañías de 75 plazas, es decir, de 750 plazas, sin contar la plana mayor, estando ésta formada por un maestre de campo, un sargento mayor y dos ayudantes, además de los capitanes, alféreces y sargentos correspondientes. Todos los vecinos, sin casi excepciones, aptos para el manejo de las armas de entre 18 y 50 años entrarían en un sorteo para servir durante un año en esta milicia, realizándose los oportunos alardes, en fechas propicias (marzo y octubre), para dotarse de la pericia militar necesaria.

Por su parte, el batallón de caballería de 1.300 plazas debía repartirse en cuatro trozos (con plaza de armas en Torrente, Castellón, Játiva y Orihuela) y, a su vez, éstos se subdividirían en treinta y dos compañías. Se reclutaría entre los más aptos de cada lugar y que tuviesen los mejores caballos. La plana mayor de cada compañía de caballería debía constar de capitán, teniente, alférez, furriel y dos cabos de escuadra ${ }^{14}$.

Las primeras reacciones fueron buenas. En marzo se insistió al virrey que cada año se hiciesen dos alardes generales con la nueva formación, y en julio de 1692 éste informaba que el alarde parcial (a causa de ser tiempo de cosecha) de tres de los tercios (Alcira, Segorbe y Onteniente) había sido muy positivo, acudiendo todos los oficiales, incluidos los de las compañías exentas de estos tercios (se eximió a las que se encontrasen a más de dos días de marcha del punto de encuentro); lo único negativo fue que "De armas está algo falta la gente, pero de aquí a la muestra del otoño se irán proveyendo como permitieren las fuerzas de los labradores"15. Una salida fue demandar a la ciudad de Valencia que pusiese a disposición del batallón el armamento depositado en la armería de la Ciudad unas 12.000 entre mosquetes y arcabuces. Una cantidad de armas extraordinaria que sería, en 1694, objeto del interés de la Monarquía, que las quería enviar a

\footnotetext{
${ }^{14}$ ACA, CA, Leg. 559/43, "Real Pragmática sacción, para que en este reyno de Valencia se forme un nuevo batallón, con nombre de la Milicia efectiva de la Custodia del Reyno...", Valencia, V. Cabrera, 1692.

${ }^{15}$ ACA, CA, Leg. 559/43, consulta del C.A., 6-III-1692 y 21-V-1692; virrey a don José de Haro, 15-VII-1692.
} 
Cataluña, donde faltaban. Ciertamente, se pidió a la Ciudad que las prestase para armar mejor el tercio del Reino enviado a servir al frente catalán. Las armas se restituyeron en $1696^{16}$.

Lo extraordinario del caso del batallón de milicia valenciano es que se intentó imponer desde la Monarquía, si no plenamente como modelo, al menos como estímulo para que los aragoneses, como veremos, desarrollasen su propia milicia

\section{ARAGÓN}

En el caso del reino de Aragón, ya en septiembre de 1665 el virrey, príncipe de Esquilache, recibió una real orden por la cual debía prevenir hasta 2.000 hombres en el Reino para la defensa de sus fronteras, si bien podrían enviarse tanto a Cataluña, como a Extremadura si fuera menester. Ante las noticias enviadas por el virrey, el Consejo de Guerra se extrañó de que el Reino pusiese algún reparo en hacer tal servicio, toda vez que las tropas iban a destinarse a la defensa de sus fronteras, de modo que acabó por aconsejar "el introducir los batallones de milicias alistando en todos los lugares el número de soldados que fuera proporcionado a su vecindad y pareziese conveniente, y que éstos se repartiesen por compañías en la misma proporción concediendo a los soldados las exempciones militares que tienen los deste género en los demás Reynos donde [h] ay estos batallones...". El Consejo de Guerra era de la opinión que si se introducía esta novedad tanto en Aragón como en Cataluña, los franceses se lo pensarían dos veces antes de invadir la Monarquía ${ }^{17}$.

De hecho, los franceses sí contaban con esta posibilidad y, a menudo, jugaron con ella. Por ejemplo, los rumores de guerra en 1672 hicieron incrementar los temores a una acción francesa relámpago en el Pirineo y condujeron al envío de trescientos hombres a defender la ciudadela de Jaca ${ }^{18}$. Ya

\footnotetext{
${ }^{16}$ S. García Martínez, Valencia bajo Carlos II, p. 291 y n. 29. ACA, CA, Leg. 571.

${ }^{17}$ ACA, CA, Leg. 70, consulta del Consejo de Guerra, 7-X-1665 y virrey a la regente, 29-IX1665. Días más tarde, el Consejo de Guerra era de la opinión que si se rompía la guerra en Cataluña, el reino de Aragón concedería que sus tropas pasasen al Principado para "...procurar alexar la guerra quanto pudieren de sus Reynos como se experimentó en los sitios de Fuenterrabía, Lérida, Tortosa y Barcelona, y hay actualmente en Badajoz, donde sirve un tercio de Aragón y otro de Valencia, que pagan los mismos reynos...". ACA, CA, Leg. 70, consulta del Consejo de Aragón, 17-X-1667.
} 
en febrero de aquel año el Consejo de Guerra había tratado sobre las noticias recibidas en el sentido de que los franceses deseaban abrir un camino carretero en dirección a Jaca, pudiendo las milicias de Béarn y Bigorre, calibradas en 20.000 infantes y 3.000 de caballería, acercarse hasta la plaza hispana ${ }^{19}$. La respuesta de don Juan José de Austria consistió en el envío de setenta hombres de guarnición a aquellos parajes, así como pedir un informe sobre el estado -lamentable fue el resultado- de la frontera aragonesa. Los avatares de aquel conflicto hicieron que los franceses, como sabemos, se decantasen por hacer la guerra en la zona más apta para mantener un ejército durante la campaña, es decir, el Ampurdán catalán, de ahí que no hubiese más inquietudes notables al respecto en la frontera aragonesa.

En realidad, antes de iniciar algún conflicto, los franceses atacaban duramente, o pretendían hacerlo, en toda la frontera pirenaica, de manera que tanteaban las diversas posibilidades de invasión al tiempo que causaban la alarma general en el territorio del enemigo. Precisamente para estar prevenidos ante dichas contingencias -en 1682 los franceses habían hecho un amago por Navarra- el rey pidió alistar 4.000 hombres en Aragón para el socorro de la frontera pirenaica; las localidades que se hallaban hasta la zona del Ebro debían enviar hacia el Pirineo aragonés un contingente de 2.000 hombres, y a partir del Ebro, y hasta completar el resto del territorio aragonés, debían enviarse otros 2.000 hombres a la frontera navarro-guipuzcoana ${ }^{20}$. Un servicio, el aragonés, puramente estacional y aparte de los dos tercios de 750 plazas que desde 1678 pagaba el Reino.

Y de nuevo, ante el inicio del último conflicto del siglo, la Guerra de los Nueve Años (1689-1697), los franceses actuaron de la misma forma. En junio de 1689, ante la noticia del estallido de la guerra y la invasión del norte de Cataluña, se le avisó al virrey de Aragón, príncipe de Cariati, que diese órdenes para tener prevenidas, armadas y alistadas las milicias del país, pero sin ponerlas en orden de batalla, puesto que se trataba de ahorrarle un gasto innecesario al Reino y, sobre todo, de no atraer al enemigo a la frontera de Aragón, como ya se había conseguido en 1638. El año de Fuenterrabía parece ser todo un referente para la

\footnotetext{
${ }^{18}$ P. SANZ CAMAÑES, Política, hacienda y milicia en el Aragón de los últimos Austrias..., pp. 279283. ACA, CA, Leg. 72, consulta del C.A., 15 y 23-VII-1672.

${ }^{19}$ ACA, CA, Leg. 71, consulta del Consejo de Guerra, 26-II-1672.

${ }^{20}$ ACA, CA, Leg. 70, consulta del C.A., 31-III-1682. ACA, CA, Leg. 72, Carlos II a diversos interlocutores, enero de 1682.
} 
defensa de Aragón ${ }^{21}$. Por lo tanto, desde Aragón no sólo se debía velar por la defensa de Cataluña, sino también por la de Navarra, de modo que se remitieron órdenes al virrey de Aragón parecidas a las de 1658 y 1684, cuando también los franceses intentaron invadir Navarra. De manera que se debían enviar a esta última todas las armas sobrantes de la Aljafería, si las demandaba el virrey de este territorio, así como tener prevenidas las milicias de Aragón. Para el virrey de Aragón, si el enemigo invadía aquellas fronteras con tropas regulares, y no con milicias del sur de Francia, no había oficiales, soldados experimentados, fortalezas preparadas ni ningún medio ni prevención, en suma, para impedírselo ${ }^{22}$.

A fines de 1689 se dieron órdenes al virrey de Aragón para que tuviese dispuestos hombres, armas y municiones para defender Fraga y Lérida -se aprestaron de la zona más cercana hasta 3.448 paisanos- en caso de avance de los franceses hacía aquellos lugares. El virrey presionó al Reino para que hiciese un donativo voluntario y certificaba que en caso de necesidad máxima podrían salir de Aragón otros dos mil hombres, si bien no todos contarían con un arma. Por ejemplo, la comunidad de Daroca señaló que contaba con 4.634 personas aptas para portar armas, pero con sólo 1.383 bocas de fuego (la mayoría de caza) $)^{23}$.

La mala marcha de la guerra sólo hizo que señalar más claramente las carencias defensivas del territorio. Desde 1691, y tras la caída de Seo de Urgel, se comenzó a percibir por parte de todos los estamentos e instituciones involucradas que la guerra iba a causar estragos una vez que las fortalezas de la frontera catalana se viesen desbordadas. Si bien se aguantó hasta 1692, a partir de la campaña de 1693 las previsiones más pesimistas se cumplieron. Ya en mayo de 1691 el virrey de Aragón dio noticias de que los franceses tenían a jornada y media de Benasque tres piezas medianas y un mortero fabricadas en torno, de manera que podían ser desmontadas y transportadas con facilidad en territorio de montaña, así como provisión de harina, que parecía iban a trasladar hacia el

\footnotetext{
${ }^{21}$ ACA, CA, Leg. 70, consulta del C.A., 25-VI-1689.

${ }^{22}$ ACA, CA, Leg. 69, consultas del C.A., 1-4-VI-1689.

${ }^{23}$ ACA, CA, Leg. 70, consultas del C.A., 13 y 19-XII-1689. También es cierto que Monzón quiso hacer un servicio de doscientos hombres para Cataluña, en plena efervescencia de la Revolta dels Gorretes (1687-1689), pero demandaron armas para esta gente, armas que no se les otorgaron porque en otras ocasiones parecidas se habían perdido muchas "y no tener medios de recobrarlas". ACA, CA, Leg. 70, virrey al C.A., 15-VI-1690. ACA, CA, Leg. 72, consulta del C.A., 30-VIII-1689 y fiscal de Aragón al Protonotario, 30-VIII-1689.
} 
valle de Arán, cuando él no tenía ninguna orden de alistar las milicias del Reino $^{24}$. O en junio de 1691, momento en el que la villa de Monzón comenzó a preocuparse por su indefensión en caso de que parte del norte de Cataluña cayese y los franceses deseasen introducirse en Aragón más allá de Lérida. La respuesta real en estos casos fue la orden de enviar armas y municiones a los naturales de la frontera con la obligación de restituirlas ${ }^{25}$.

Desde Zaragoza, el fiscal del Reino, Carlos Bueno, daba noticias muy negativas procedentes de la frontera, señalando que se iba reconociendo cuanta gente se podría alistar, pero que faltaban armas y municiones en todas las universidades; asimismo, informaba de cómo se habían registrado todos los forasteros que había en la Ciudad con ánimo de expulsarlos de la misma para evitar cualquier incidente y, por último, que se consideraba que si desde Aragón se juntaba un pequeño contingente para resistir al enemigo "y el señor duque de Medina Sidonia pudiese con su exército cortarle el paso para la retirada, sería muy factible acabar con todo el exército que tiene aquí el francés, pero la flaqueza de nuestras fuerzas y haver tan poco dinero en este Reyno no pueden dar mucho lugar a estas esperanzas"26. Dichas noticias se mezclaron con las que llegaron directamente de la frontera, cuando el Consejo de Aragón supo que no sólo había caído Seo de Urgel, sino que también habían entrado "algunos michaletes y gitanos franceses hasta numero de 300 que andan robando y llevando los ganados de muchos lugares de las fronteras de Cataluña...". Los jurados de Zaragoza y los diputados del Reino comenzaron a reclamar la presencia en su tierra del tercio que pagaban situado en el ejército de Cataluña (con el transcurso de los años, los dos tercios aragoneses se habían reducido a tan solo uno), así como el envío de otras formaciones militares tanto de

\footnotetext{
${ }^{24}$ ACA, CA, Leg. 67, consulta del C.A., 26-V-1691. Decía el Consejo de Aragón que en el Reino aragonés no había "milicias de calidad que puedan obrar por la pobreza de aquellos naturales y falta de armas en una invasión", de modo que instaban a que se enviase armas a la frontera, como ya se hizo cuando hubo peligro de invasión del valle del Roncal el año anterior, pero sólo si era necesario.

${ }^{25}$ ACA, CA, Leg. 68, virrey al protonotario de la C.A., 15-V-1691 y protonotario al virrey de Aragón, 26-V-1691; ACA, CA, Leg. 69, jurados de Monzón al virrey, 17-VI-1691 y consulta del C.A., 21-VI-1691. En buena medida, las noticias negativas se habían difundido desde Cataluña, donde esperaban un ejército francés incrementado con 12.000 hombres procedentes de su ejército de Italia y el concurso de su armada que operarían conjuntamente con la intención de expugnar Rosas. ACA, CA, Leg. 68, consulta del C.A., 7-VI-1691, con cartas de los jurados de Zaragoza y diputados de Aragón.

${ }^{26}$ ACA, CA, Leg. 68, don Carlos Bueno al protonotario, 12-VI-1691.
} 
infantería como de caballería. Los síndicos generales del condado de Ribagorza demandaban tropas, armas y municiones para defender su tierra, "antemural de este reyno por esta frontera". Sólo entonces, al ver la situación más apurada, Carlos II solicitó una movilización general como la de 1638 para Fuenterrabía -"Y porque tengo entendido cuando sucedió el sitio de Fuenterrabía se convocaron las universidades de orden del gobernador de ese reyno para la defensa de él y socorrer al de Navarra, mi voluntad es que se ejecute lo mismo en esta ocasión"- a su virrey, tratando éste primero con la gente más adecuada y trasladando después sus planes a los diputados de Aragón y lo jurados de Zaragoza. La idea era enviar toda la gente alistada donde hiciese más falta, "ya sea a las montañas o a las fronteras de Cataluña y aún entrando en el mismo Principado si el enemigo bajase a Lérida, pues en la defensa de esa ciudad es igualmente interesado ese reino...", de manera que las instituciones aragonesas no podían negar que sus tropas saliesen de la raya de Aragón. Para no causar molestias a los lugares de la frontera, las milicias aragonesas debían estar perfectamente disciplinadas (para ello se proveería una patente de sargento general de batalla) y mantenidas gracias a los suministros enviados por las universidades del Reino ${ }^{27}$. Un problema inmediato era saber exactamente la cantidad de personas útiles y las armas de las que disponían para salir a campaña ${ }^{28}$.

El Consejo de Aragón, por su parte, agradeció las muestras de fidelidad del Reino, pero recomendó al rey que no se sacasen tropas de Cataluña, puesto que la invasión francesa del Pirineo aragonés, en caso de producirse, sería sólo una distracción de su objetivo, de manera que se le debía hacer frente con las milicias aragonesas que se pudieran juntar; no obstante, reconocían que había que enviar medios para mejorar las fortificaciones de la frontera, que los aragoneses por sí solos no podrían, y que se remitirían las 500 picas y las patentes de oficial necesarias para poner las milicias aragonesas en servicio ${ }^{29}$. El virrey de Aragón, en cambio, era consciente de la necesidad de que algunos lugares de la frontera, cuyos hombres carecían de disciplina militar, debían ser socorridos por infantería y caballería del ejército de Cataluña ${ }^{30}$. La respuesta del rey a todas estas urgencias fue que como el estado de la Real Hacienda y los muchos gastos

\footnotetext{
${ }^{27}$ ACA, CA, Leg. 67, Carlos II al virrey, minuta, 20-VI-1691.

${ }^{28}$ ACA, CA, Leg. 67, Virrey al rey, 7 y 12-VI-1691; consulta del C.A., sin fecha, fines de junio de 1691.

${ }^{29}$ ACA, CA, Leg. 68, consulta del C.A., 22-VI-1691. ACA, CA, Leg. 67, síndicos generales del condado de Ribagorza al virrey, 14-VI-1691.
}

${ }^{30}$ ACA, CA, Leg. 67, virrey al rey, 17-VI-1691. 
que había impedían el envío de cantidad alguna a Aragón, que del donativo de 17.000 pesos que ofreció el propio Consejo de Aragón se le remitiesen 4.200 al virrey, príncipe de Cariati, para que los administrase con mucho cuidado y aplicase a la defensa de la frontera ${ }^{31}$. Los diputados de Aragón, a su vez, además de agradecer el nombramiento del conde de Guara como sargento general de batalla, rogaban que los otros veinticuatro capitanes reformados que el rey había prometido enviar para mejorar la disciplina militar de las milicias aragonesas fuesen alféreces y sargentos naturales del Reino que sirviesen por aquel entonces en el ejército de Cataluña, donde ya tendrían un sueldo asignado, ascendiendo a aquellos que lo mereciesen. Por otro lado, reclamaban más medios a Carlos II para la defensa de la frontera, pues no llegaban a cubrir todos los gastos ${ }^{32}$. Pero el virrey, en nueva carta de fines de junio, no pudo excusar decir que entre tanta discusión con unos y otros se acababa haciendo muy poco, casi nada, mientras los pueblos clamaban desprevenidos. Su análisis de la visión egoísta del asunto, según los intereses de cada uno, no tiene desperdicio: para el príncipe de Cariati, los particulares de Zaragoza, que tenían censales y otros intereses en la Ciudad y el Reino, "publican que el enemigo no puede hacer invasión alguna y que la frontera necesita de muy corta asistencia; los ambiciosos de graduaciones desean levas, los que tienen pocas conveniencias ser empleados para tener socorros...". El virrey era consciente de lo que explicaba, pero también se expresaba con libertad por estar al final de su trienio. Aseguraba que gente realmente útil para el servicio en todo Aragón sólo había de 6.000 a 8.000 hombres, y armados apenas 4.000, y en los lugares más inmediatos al frente tan sólo 1.500; eso sí, armados gracias al material remitido por él y los diputados desde Zaragoza. La Ciudad tenía más armamento, pero lo reservaba para sus vecinos. Las fortificaciones de Benasque, Aren, Benabarre y el puente de Montañana necesitaban reparación, si bien podría haber buena disposición de los naturales en trabajar en estas obras. Con todo, lo más alarmante para el virrey era que más que discutirle las órdenes, debía repetirlas una y otra vez, malgastando un tiempo precioso ${ }^{33}$. La recomendación que se le hizo al virrey desde Madrid poco después era que procurase "establecer en aquel reyno tercios milicianos como los que hay en Valencia, Navarra y Extremadura, y que estos no

\footnotetext{
${ }^{31}$ ACA, CA, Leg. 67, consulta del C.A., 19-VI-1691.

${ }^{32}$ ACA, CA, Leg. 67, diputados al rey, 26-VI-1691. En minuta del 11 de julio, el C.A. respondió que no se podían sacar oficiales del tercio aragonés que servía en el ejército de Cataluña. ACA, CA, Leg. 67, minuta del C.A., 11-VI-1691.

${ }^{33}$ ACA, CA, Leg. 67, virrey al protonotario de Aragón, 26-VI-1691.
} 
han de ser para salir a servir fuera del, sino quando se ofrezca una invasión como la presente estar promptos para acudir a la defensa de las fronteras, y que han de estar disciplinados y con las armas necesarias para las ocasiones de urgencia...". Por otro lado, no se debía dejar pasar la ocasión de tantear si el Reino estaba dispuesto a pagar nuevos tercios para el ejército de Cataluña ${ }^{34}$.

Por su parte, los diputados de Aragón, ante la necesidad de presentar una planta de las nuevas milicias que se pudiesen levantar en el Reino, desarrollaron la siguiente: se establecerían cuatro tercios de 1.000 plazas, divididos en diez compañías de cien hombres con los oportunos oficiales, que, a su vez, serían levados en uno de los cuatro partidos en que se dividiría Aragón. Las ciudades y comunidades elegirían a los oficiales de las compañías que levantasen, estando alistados sus habitantes; entre ellos saldrían aquellos que sustituyesen las bajas que se produjesen, estando los que sirvieran exentos de alojamientos y tránsitos de tropas. Todos los domingos se repartirían las armas y municiones y se harían los oportunos ejercicios militares, teniendo los sargentos mayores de cada tercio la obligación de pasar muestra cada seis meses. Los maestres de campo también pasarían muestra en una plaza de armas elegida los meses de octubre y abril de cada año. Para los diputados con cuatro tercios era suficiente, evitándose más embarazos a la población, si bien siempre era factible alistar más tropas si fuese oportuno. De momento eran necesarias cuatro patentes de maestre de campo, otras tantas de sargento mayor, treinta y seis de capitanes, cuarenta de alféreces y ocho de ayudantes ${ }^{35}$. Pero, al mismo tiempo, aprovecharon la coyuntura para dejar claro al rey que los naturales que se alistasen en la milicia no debían, posteriormente, encuadrarse en ninguna leva que tuviese por destino servir fuera del Reino ${ }^{36}$. La Real Audiencia, al tratar la planta propuesta por los diputados, simplemente recordó que dado que el rey pagaría aquellas tropas, debía ser el virrey quien en última instancia controlase la oficialidad de los cuatro tercios (la plana mayor) y no los diputados, si bien el rey podría permitir a las universidades elegir a los capitanes y que se les concediesen algunas exenciones para estimular la recluta. Los jurados de Zaragoza, por cierto, sólo admitían hacer tres tercios de mil plazas y dejando, además, el negocio para $1692^{37}$.

\footnotetext{
${ }^{34}$ ACA, CA, Leg. 68, consulta del C.A., 11-VII-1691.

${ }^{35}$ ACA, CA, Leg. 67, Diputados de Aragón al rey, 24-VII-1691.

${ }^{36}$ ACA, CA, Leg. 67, Diputados al rey, 14-VIII-1691.

${ }^{37}$ ACA, CA, Leg. 67, Real Audiencia de Aragón al virrey, 17-IX-1691. En carta del día siguiente a Carlos II, el virrey estaba de acuerdo. ACA, CA, Leg. 66, jurados de Zaragoza a Carlos II, 14VIII-1691.
} 
A fines de enero de 1692 se reanudó el negocio de las milicias aragonesas. La Real Audiencia de Aragón señalaba que pensaban que los cuatro tercios provinciales de Aragón podían quedar repartidos de la siguiente forma: de la ciudad de Zaragoza y lugares circunvecinos quinientos hombres; de Calatayud, Daroca y sus comunidades hasta ochocientos; de Teruel, Albarracín y bailías colindantes otros ochocientos hombres; de Tarazona, Borja y las comunidades comprendidas entre los ríos Ebro y Jalón y hasta el río Aranda, quinientos hombres; en las Cinco Villas y su partido, trescientos hombres; en Huesca, Barbastro y demás lugares entre el río Gállego y el Cinca, quinientos hombres y, por último, en Alcañiz y bailías colindantes, seiscientos hombres. Estas tropas debían entrenarse en ejercicios militares, de manera que el gasto efectuado corriese por cuenta de las universidades, si bien el rey debería enviar las armas $\mathrm{y}$ municiones que faltasen, una petición muy recurrente. El rey, recordaban, por su disposición del año anterior acerca de este asunto, debía pagar estas tropas en cuanto saliesen hacia la frontera.

El Consejo de Aragón estimó que el Reino podía llegar a alistar otros cuatro mil hombres y, además, debería pagar estas tropas algún tiempo, toda vez que el tercio del conde de Guara iba a ser pagado durante tres semanas por el condado de Ribagorza cuando saliese a defender la frontera ${ }^{38}$. Para el Consejo de Aragón, la mejor opción era intentar que todo el Reino realizase un servicio parecido al ajustado con el condado de Ribagorza, aunque sólo pagasen las tropas por tres semanas -una situación que siempre podría cambiarse-, pues lo interesante era contar con una colaboración de tal magnitud y un precedente como este a seguir, pues se calibraba en otros cuatro tercios de mil hombres las posibilidades reales de Aragón, pero no mucho más dadas las dificultades económicas del Reino y el reducido número de sus habitantes ${ }^{39}$.

El nuevo virrey de Aragón, marqués de Camarasa, comenzó a informar de la dificultad de lograr levantar los tercios provinciales en Aragón por "la considerable falta de gente" que había en el Reino ${ }^{40}$. Es más, señaló que, incluso, el condado de Ribagorza ofrecía entonces sólo 300 hombres para aquella campaña y que el famoso tercio del conde de Guara tan sólo era una promesa hecha al mismo por las autoridades de la zona que, además, estaban "disidentes" del conde. Es decir, ni siquiera se podía contar firmemente con la tropas que

\footnotetext{
${ }^{38}$ ACA, CA, Leg. 67, consulta del C.A., 8-II-1692.

${ }^{39}$ ACA, CA, Leg. 68, consulta del C.A., 15-II-1692.

${ }^{40}$ ACA, CA, Leg. 68, veedor del tercio al protonotario, 17-V-1692; consulta del C.A., 10-VI1692; virrey al rey, 29-VII-1692.
} 
pagaba estacionalmente el condado y que, con el tiempo, se habían transformado en un referente para las milicias aragonesas.

El Consejo de Aragón pidió al rey que ordenase a su virrey a tratar con diputados, jurados de Aragón y demás personalidades del Reino la posibilidad de levantar los cuatro tercios de las milicias provinciales, olvidándose momentáneamente del servicio del condado de Ribagorza. De todas formas, la cercanía del condado de Ribagorza a Cataluña hacía su esfuerzo de guerra casi indispensable, sobre todo ante la voluntad francesa por aposentarse en el Pirineo catalán ${ }^{41}$. Pero el rey aceptó la sugerencia del Consejo y aquel invierno se trató arduamente con los gremios el alistamiento de su gente para el servicio en las milicias provinciales.

Tras muchas discusiones, en la primavera de 1693 el arzobispo de Zaragoza pudo informar que la Ciudad admitía formar dos tercios de 700 plazas cada uno de ciudadanos y gentes de los gremios, esperando sólo del rey la remisión de patentes en blanco para dotar de oficialidad a dichos tercios de milicias con los naturales más convenientes. Para el virrey aquella era una gran noticia, pues a partir del ejemplo zaragozano se trataría de lograr un servicio parecido en el resto del Reino, comenzándose los alardes para formar la gente. Se les respondería que donde existían estas milicias -Navarra, Valencia y Extremaduraera el propio virrey quien concedía las patentes de oficiales, puesto que no eran estas tropas para incorporar al ejército, sino para defender las fronteras del Reino. Los jurados escribieron para pedir al rey el envío de quinientas picas para ejercitar a los ciudadanos en el manejo de las armas, toda vez que mosquetes y arcabuces había suficientes para tal fin ${ }^{42}$.

Tras la caída de la plaza de Rosas, los diputados catalanes reclamaron un mayor esfuerzo de guerra tanto a la Corte como a los reinos de la Corona de Aragón, pues percibían que el frente podía hundirse en cualquier momento. El virrey de Aragón contestó que presionaba tanto a los diputados como al cabildo para que se hiciese el mayor esfuerzo posible, aprestando las milicias provinciales para intentar enviar el mayor número de efectivos al Principado, toda vez que era Aragón un "Reyno abierto y no haver ciudad ni pueblo con

${ }^{41}$ ACA, CA, Leg. 67, consulta del C.A., 15-VII-1692; virrey al protonotario, 22-VII-1692; virrey al rey, 12-VIII-1692.

${ }^{42}$ ACA, CA, Leg. 68, relación de la gente del tercio, 26-I-1693; Junta del servicio, 27-I-1693. ACA, CA, Leg. 70, consulta del C.A., 19-IV-1693. ACA, CA, Leg. 68, virrey al rey, 21-IV-1693; jurados de Zaragoza a Carlos II, 21-IV-1693. 
murallas ni castillo que pueda fortificarse ni ponerse en defensa regular...", por lo que Cataluña era el auténtico "antemural" no sólo de la Monarquía, sino de Aragón en particular ${ }^{43}$. El esfuerzo de guerra reclamado se tradujo finalmente en levar un tercio extraordinario de 1.000 plazas vestido, conducido a Cataluña y mantenido en la misma durante una campaña por el Reino, que pagaría 600 de los mismos, y la ciudad de Zaragoza, que haría lo propio con 400. También señaló el arzobispo que halló en su momento en la armería que tenía el rey en el palacio de la Aljafería 4.630 mosquetes, arcabuces y escopetas, "...pero en tan mala disposición que estaban los arcabuces y mosquetes en el suelo, la pieza húmeda y maltratada, las armas tomadas de la humedad... e hizo componer otra pieza más capaz y de mejor terreno, labrar y poner estantes y que se limpiase por dentro y fuera los mosquetes y arcabuces y se aderezasen algunos que les faltaban tornillos y limpiaderas..." ${ }^{14}$.

Desde octubre de 1693, Carlos II comenzó su ofensiva para que tanto Aragón, como Valencia y la propia Cataluña hiciesen un esfuerzo supremo de cara a la campaña de 1694 enviando al frente las formaciones más nutridas que pudiesen ${ }^{45}$. Y desde Aragón, el virrey duque de Escalona, pedirá al presidente del Consejo de Aragón, duque de Osuna, que el rey remitiese cartas tanto a él como a los diputados demandando que se hiciese una quinta general en el Reino, sistema que ya se había utilizado en otras ocasiones, dado que percibía que, si bien Aragón había hecho un máximo esfuerzo en los donativos suministrados, las levas de voluntarios experimentaban allá suma dificultad "por la falta de gente y de inclinación a la milicia". El Consejo de Aragón estuvo de acuerdo en plantear una quinta voluntaria, sacando un soldado de cada cincuenta fuegos, "y estos tan voluntariamente que si algún lugar se escusare se admitiría su escusa sin desagrado". El rey aceptó prometiendo que cada hombre levado de esta manera sería conducido a Cataluña, mantenido y pagado por el tesoro real, retornando a su casa al término de la campaña, señalando que "si por sólo ganar gloria emprendieron sus naturales en lo pasado tantas y tan grandes conquistas

\footnotetext{
${ }^{43}$ ACA, CA, Leg. 70, virrey a Carlos II, 16-VI-1693.

${ }^{44}$ ACA, CA, Leg. 69, consulta del C.A., 22-VI-1693. ACA, CA, Leg. 66, consulta del C.A., 30VI-1693. En otra consulta del 22 de junio, los consejeros señalaban al rey que la ciudad de Zaragoza demandaba patentes para los oficiales de los tercios de milicianos que se realizaban, pero que no tenían derecho puesto que eran tropas que defenderían el Reino y que, en principio, no tenían previsto unirse al ejercito real en Cataluña. Zaragoza insistía en que, como servicio de tropas que era, tenían derecho a nombrar los oficiales. De momento, el rey suspendió el envío de las patentes de oficial. ACA, CA, Leg. 75, consulta del C.A., 22-VI-1693
}

${ }^{45}$ ACA, CA, Leg. 67, Carlos II al duque de Osuna, 23-X-1693. 
dilatándose hasta el imperio Griego, con más razón deva esperar en lo presente que por defensa de la Corona y de sus propias casas pasarán a una provincia vecina a quebrantar las fuerzas de el (sic) enemigo mostrando lo que puede su valor en mi servicio...". Carlos II demandaba el servicio toda vez que no podía desplazar tropas extranjeras a Cataluña que servían en Flandes e Italia ${ }^{46}$.

Pero se hizo muy poco al respecto. De hecho, el nuevo virrey, duque de Jovennazo, indicó que la quinta que había apalabrado su antecesor el duque de Escalona y marqués de Villena con el Reino fue frenada en su ejecución por el propio Escalona, y si bien, decía Jovennazo, "yo ygnoro los motivos, se ha ofrecido a reparo del malísimo sonido que haze en este Reyno todo lo que mira a tributo, y aunque el servicio que V. Mag. pide viene a ser puramente gracioso, la tasa de un soldado por cada 50 fuegos (que es ya pública) tengo fundados resquentros de que fuera muy mal recivida...", por ello estaba buscando la forma de pedir el servicio de la forma más aceptable y, por lo tanto, también más efectiva. El Consejo de Aragón apoyaba totalmente la manera de actuar del virrey $^{47}$. Ciertamente, más que un donativo, los aragoneses vieron en esta petición un tributo. Por ello, se decidió enviar personas apropiadas a hacer la petición de la quinta por todo el Reino, dejando bien claro que la gente que se levantara sería pagada por el rey (pero con los efectos de los donativos concedidos por el Reino, básicamente) ${ }^{48}$. El virrey reconoció poco después que en dicho negocio las universidades no podían obligar a los vecinos a hacer un servicio de tal naturaleza, de manera que, si todo dependía de la voluntad de los mismos, nadie podía extrañarse que si a lo largo del invierno sólo se habían levantado 400 hombres, durante aquella primavera serían muchos menos ${ }^{49}$. Además, se acabó solventando una cierta "irregularidad" cometida por el virrey Escalona-Villena, que demostraba de paso sus pocas luces políticas -poco después demostraría las pocas militares que tenía en Cataluña-, pues se logró que el rey destituyera a los oficiales confirmados por Escalona-Villena al frente de las compañías que levaban las universidades aragonesas, siendo sustituidos por naturales ${ }^{50}$.

\footnotetext{
${ }^{46}$ ACA, CA, Leg. 70, Escalona a Osuna, 1-XII-1693, consulta del C.A., 5-XII-1693, carta borrador del rey, 6-XII-1693.

${ }^{47}$ ACA, CA, Leg. 69, virrey al rey, 9-II-1694 y consulta del C.A., 13-II-1694.

${ }^{48}$ ACA, CA, Leg. 68, consulta del C.A., 21-II-1694. ACA, CA, Leg. 67, diputados al rey, 14-II1694.

${ }^{49}$ ACA, CA, Leg. 67, virrey al rey, 23-II-1694.

${ }^{50}$ ACA, CA, Leg. 67, virrey al rey, 9-III-1694.
} 
Las noticias de la derrota del río Ter en mayo de 1694 y la caída de Gerona se mezclaron con las que dieron los diputados de Aragón sobre el negocio de la formación de las milicias provinciales desde 1691, planteándose de nuevo levantar cuatro tercios de mil plazas cada uno, distribuyéndolos por las universidades del Reino, pensándose también en la forma de adiestrar a estas tropas. El coste era de 200.000 libras aragonesas (dos millones de reales castellanos). En las circunstancias del momento, la petición tenía más sentido que nunca y los diputados eran conscientes de ello, por lo que no dudaron en ponerse a disposición del virrey para ultimar este negocio ${ }^{51}$. El rey deseaba que se tratase con "vigor de perfeccionar la obra empezada de la formación de los tercios milicianos en aquel reyno para que hay un cuerpo de gente alistada de que valernos en el caso referido, dándose entonces providencia al sustento de ella"52. Pero en enero de 1695 no se tenían noticias de este negocio, que ya estaba muy adelantado en Valencia, Castilla, Andalucía y Extremadura, por lo que se pidió al virrey de Aragón que acelerase la consecución del mismo ${ }^{53}$. Sin duda, había que resolver un problema previamente. La ciudad de Zaragoza reclamaba que los oficiales de los tercios milicianos recibiesen patente real para ejercer sus grados. El rey aseguró que así se haría, pero algo falló puesto que más tarde se insistiría en lo mismo ${ }^{54}$.

En enero de 1695 se les remitió a las autoridades aragonesas una copia del reglamento de milicias elaborado por el virrey de Valencia, marqués de Castel Rodrigo, y, de paso, el rey apremió al duque de Jovennazo, virrey de Aragón, en el sentido de acelerar la formación de los tercios de milicianos ${ }^{55}$. En febrero los diputados se defendieron diciendo que habían escrito a todo el mundo para acelerar aquel negocio y el virrey remachó la noticia al asegurar que en todo momento habían seguido reclamando patentes en blanco para dotar a la oficialidad de los tercios milicianos, cuestión "en la qual los he visto siempre invencibles". El virrey señalaba que la disposición de los autoridades aragonesas al respecto siempre había sido mínima, que todo eran discursos, de manera que en ningún caso podrían disponer de los 8.000 hombres con los que se suponía se contaba. Quizá para acabar con un asunto al que no le veía un buen final, el

\footnotetext{
${ }^{51}$ ACA, CA, Leg. 70, Diputados de Aragón a Carlos II, 6-VII-1694.

${ }^{52}$ ACA, CA, Leg. 75, el rey al duque de Osuna, 19-V-1694.

${ }^{53}$ ACA, CA, Leg. 70, junta presidida por el duque de Medina Sidonia, 5-I-1695.

${ }^{54}$ ACA, CA, Leg. 75, jurados de Zaragoza al rey, 22-VI-1694. El mismo asunto se había pedido justo un año antes, el 16-VI-1693, sólo que para las tropas extraordinarias enviadas a Cataluña.

${ }^{55}$ ACA, CA, Leg. 67, protonotario de Aragón a don Bartolomé Ordovás, 2-II-1695, y Carlos II al virrey de Aragón, febrero de 1695.
} 
virrey reflexionó que, en todo caso, aquella gente debería cobrar dos reales al día, que multiplicados por su número, implicaba disponer de 16.000 reales diarios, cifra a la que se debía añadir primeras planas, bagajes y otros gastos, y si en dos días faltaba la paga se disolvería la fuerza. Por último, como cantidad que no admitía mucha discusión teniendo en cuenta las dificultades de aquellos años, el virrey creía necesitar unos 560.000 reales... "No digo esto por que tales consideraciones [h] ayan de entibiar ni atrasar mis diligencias, pero solamente a fin de que no se hagan cuentas alegres que tantas veces han costado caras". Al final, el marqués de Jovennazo se conformaba con levantar algunas milicias de los lugares más cercanos a la frontera catalana, más dispuestos a aquel servicio por la cuenta que les traía y más barato al no tener que desplazarse desde tan lejos.

Por otro lado, se le pidió al señor José Celaya su opinión sobre la formación de los batallones de milicianos en el Reino. Tras explicar que nunca se habían enviado las patentes de oficial, excusa perfecta para las autoridades aragonesas en el sentido de impedir que éstas aceptasen realizar el servicio, Celaya ofreció algunas opiniones muy interesantes. Por un lado, con una fuerza de sólo 4.000 hombres, si es que se alistaban todos, no se podría impedir la invasión de los franceses desde Cataluña, habida cuenta que no existían fortificaciones más allá de Lérida; con tan poca gente, los naturales sospechaban, en realidad, que se buscaba una recluta encubierta para enviarlos fuera del Reino. Por otro lado, al ser tan poca la gente alistada habría demasiadas quejas de éstos por los muchos que se habían librado del servicio de armas, además de que sólo con los días de fiesta para ejercitarse y en un lugar pre-establecido y lejano para muchos de ellos, sin contar la disposición o no de armas en buen estado, dificultaba mucho este negocio. En realidad, habría menos problemas si en lugar de alistar cuatro mil personas, mil por batallón, se alistaban 16.000, divididas en compañías de doscientos hombres que se ejercitarían en un lugar distante, como máximo, tres o cuatro leguas a sus hogares. Como todas las universidades presentarían candidatos para la oficialidad, el rey debería elegirlos entre los mejores; también confiaba en que hubiese armas suficientes para todos los hombres, o bien subsanar este problema lo antes posible. Celaya explicaba, asimismo, que la situación económica no permitía muchas alegrías en Aragón y que el año anterior, cuando se hizo un gran es fuerzo, se arrastró al servicio a "quantos por causas leves estaban criminalmente procesados, quantos turbaban la paz de las universidades, y quantos se arrimaban a seguir la guerra; escaparon pocos y el haber sido tan pocos les hará ser menos por más que la diligencia se adelante...", de manera que no esperaba que se consiguiese levantar mucha gente para aquel año. Celaya consideraba que se debía elegir ya cuatro maestres de campo naturales y cuatro sargentos mayores y ocho ayudantes no regnícolas si era 
necesario, "si en Aragón no se hallasen con la inteligencia militar que piden los ensayos", que todos cobrasen los sueldos correspondientes y que desde Zaragoza se dinamizase la formación del batallón propio para alentar al resto del Reino. El alistamiento debía ser de todos los mozos útiles y no debería escatimarse el hecho de salir a la raya del Reino -o incluso fuera- a defenderse, pues Lérida, pero también Fraga, Monzón o Berbegal serían sus únicas defensas si caía Barcelona. Además, en un momento dado estas tropas podrían unirse al ejército de Cataluña para derrotar a los franceses, siempre bajo su criterio, pues es obvio que "...fuera su mejor resguardo el que tuviesen en país ajeno, preservados de las ruinas que dejan las campañas". Celaya concluía recordando que el rey sólo debía pagar los sueldos de los oficiales de la plana mayor y el gasto de las municiones, siendo la formación de aquel ejército un servicio del Reino por su propio bien. Con aquella conclusión, ya se podía intuir que aquellas disposiciones iban a tener poca fortuna ${ }^{56}$. Como así ocurrió.

\section{MALLORCA}

Con relación a la defensa, era competencia del Gran $i$ General Consell mallorquín mantener algunas naves de guerra, una compañía de cien artilleros que cuidaban las piezas instaladas en las fortalezas, así como la compañía de arcabuceros, más tarde mosqueteros, denominada dels doscents. La milicia de la Universitat estaba formada por veinte compañías (desde 1584), además de la compañía permanente antes mencionada. En 1693 estas tropas sumaban 3.000 hombres. Además, había cuatro compañías de caballería voluntaria.

Las restantes villas del Reino contaban con su propia milicia conformada, asimismo, por cuatro tercios, dirigidos por un maestre de campo y un sargento mayor, divididos en varias compañías mandadas por un capitán. La caballería de la parte foránea se dividía en nueve batallones. En 1692, por orden el virrey marqués de Villatorcas, se realizó una muestra de la infantería, caballería, dragones, municiones y piezas artilleras que se hallaban en servicio en las treinta y cuatro villas de la parte foránea del Reino de Mallorca. Los resultados fueron los siguientes: los cuatro tercios (De la Puebla, De la Montaña; San Lorenzo y Campos) se dividían en 31 compañías, éstas contaban con un total de 16.594 infantes, 700 caballos forzados, otros 189 voluntarios y 798 dragones. Su armamento era: 436 mosquetes, 6.049 arcabuces, 5.992 escopetas, 342 picas y 6.830 espadas. Un armamento claramente inferior a lo necesario, reclamándose

\footnotetext{
${ }^{56}$ ACA, CA, Leg. 76, don José Celaya a destinatario desconocido, 8-I-1695.
} 
otros 5.932 arcabuces y 9.370 espadas. Además, en las treinta y tres torres y ocho fortalezas de la costa mallorquina había 92 soldados de guarnición, que cobraban 4.223 libras al año; contaban con 41 cañones (doce de bronce y el resto de hierro), 109 espingardas, 70 mosquetes, 130 arcabuces y 67 botavantes. De pólvora había en total 102 quintales, de balería 217 quintales y de cuerda 599 quintales ${ }^{57}$.

Tales cifras son acordes con otros registros del armamento existente en la isla. En Mallorca se hicieron tres visitas ${ }^{58}$, que conozcamos, para controlar el nivel de armamento de la población: en 1585 aparecieron 20.705 armas, de las cuales arcabuces había 10.214 (49,3\%) y mosquetes 314 (1,51\%). En 1667, los datos son los siguientes: 21.019 armas registradas, de las cuales arcabuces eran $12.074(57,44 \%)$, mosquetes $689(3,27 \%)^{59}$ y escopetas $5.986(28,47 \%)$. Pero igual de reseñable es el hecho que de las 3.168 ballestas que había en 1585, en 1667 no quedaba ninguna; mientras que el número de lanzas y picas se redujo entre ambas fechas en un $62,37 \%{ }^{60}$.

El rey mantenía en Mallorca tropas de infantería, artillería (una compañía desde 1592) y de caballería -que en 1683 comprendía cinco compañías. Los oficiales del rey en Mallorca eran un general de la caballería, tres maestres de campo, un capitán de la artillería del Reino, un capitán de la artillería real, el sargento mayor de Palma, el capitán de la caballería real y el capitán y gobernador de Alcúdia. Los asuntos que afectaban a la defensa se ventilaban en un consejo de guerra presidido por el virrey pero en el que también estaba presente el jurat en cap del Consell del Reino ${ }^{61}$.

\footnotetext{
${ }^{57}$ ACA, CA, Leg. 965.

${ }^{58} \mathrm{La}$ de 1515 dio como resultado 7.270 lanzas, 31 picas, 1.375 ballestas, 27 trabucos, 17 espingardas, 6.437 espadas, 1.348 corazas, 37 petos, 12 coseletes, 938 paveses, 293 rodelas y 6 arneses. Véase, F. WeYler, Historia orgánica de las fuerzas militares de Mallorca, desde su conquista en 1229 hasta nuestros días, Palma de Mallorca, 1862, p. 90. Según este autor, a causa del aumento de la población mallorquina, en 1648 existían de 8.000 a 10.000 hombres que carecían de armas, p. 100.

${ }^{59}$ Según F. Weyler, en 1658 la Universidad tenía en depósito 447 arcabuces, 1.893 mosquetes, 222 mosquetes de muro, 62 carabinas de rueda, 1.427 picas, 34 chuzos, 573 espadas y 208 arneses completos. Véase F. WeYLER, Historia orgánica de las fuerzas militares de Mallorca, p. 109.

${ }^{60}$ J. Serra i Barceló, "El bandolerismo en Mallorca durante el reinado de Felipe II", en VV. AA., Felipe II y el Mediterráneo. Vol. II: Los grupos sociales, Madrid, 1999, p. 466.

${ }^{61}$ Román PIÑa Homs, El Gran i General Consell. Asamblea del Reino de Mallorca, Palma de Mallorca, 1977. Antoni I. Alomar, L'exèrcit mallorquí. De la fi de l'edat mitjana a la seva desaparició, Palma, 1998.
} 
La principal problemática al respecto en Mallorca era el difícil equilibrio entre los servicios de armas que ofrecía el Reino a la Monarquía (voluntarios que servían en el Corso, leva de tercios pagados por el Reino, permisión de recluta de tropas mediante asiento) y la necesidad de mantener una milicia lo suficientemente entrenada y bien armada como para poder repeler, dado el caso, una invasión de la isla; invasión que, más que por la parte de Palma, cabía esperarla por Alcúdia, dada la capacidad de sus bahías para acoger no una, sino varias armadas enemigas. Un virrey como el marqués de Sentmenat fue especialmente sensible a estas cuestiones, así como el sargento mayor de la ciudad de Palma, además de otras muchas cosas, Vicente Mut ${ }^{62}$.

Ibiza contaba con una milicia compuesta por seis compañías, en las que se alistaban los hombres útiles de 16 a 60 años, dirigidas por un capitán, elegido por el gobernador, con un salario de veinte libras al año, un alférez y un sargento, designados por el capitán con la aprobación del gobernador, que cobraban quince y diez libras, respectivamente. Los cabos de escuadra, ocho en la compañía de la Ciudad, cobrarían cinco libras al año. El alférez de la caballería gozaba de un estipendio de quince libras anuales. La compañía de caballería que había en la isla era pagada por el rey, el arzobispo de Tarragona (ocho caballos) y el arcediano de San Fructuoso (tres caballos), como conseñores de la isla. Asimismo, existía una compañía de artilleros. Cada domingo, todo el que tuviera arma de fuego debía ejercitarse, procurándosele pólvora, pagada por la Universitat, para hacer estos ejercicios militares. También se instituyó en 1663 que cada año se gastarían cincuenta ducados en la compra de regalos para repartir entre los mejores tiradores de la isla ${ }^{63}$.

Llegado en la primavera de 1666 a Ibiza, Jerónimo García, comisario general de la caballería, pasó lista a los efectivos militares de la isla y el resultado fue el siguiente: la compañía de infantería pagada por el rey constaba de 190 plazas, incluidos los oficiales; la compañía de caballería tenía 70 plazas;

\footnotetext{
${ }^{62} \mathrm{~V}$. Mut, Instrucción para la milicia y sus oficiales que se ha de observar en caso de la invasión ó tocar arma en la isla de Mallorca, Palma de Mallorca, R. Moyá, 1674; e Instrucción general para la gente y officiales de guerra del presente Reyno de Mallorca, tanto por la parte forana como para dentro de la Ciudad, y Ordenes que se han de observar. Por Orden del ilustrisimo Sr. D. Emanuel Sentmant, y de Lanuza, virrey y Capitán General del mismo Reyno, Palma de Mallorca, R. Moya, T. y J. Bestard, 1683.

${ }^{63} \mathrm{M}$. TORRES, La llengua catalana a Eivissa al segle XVII, "Reials ordinacions de la Universitat d'Eivissa" (1663), Ibiza, 1993, pp. 486-489. I. MACABICH, Historia de Ibiza, Palma, 1966, Vol. I, p. 211.
} 
la compañía de artilleros contaba con plazas dobles y sencillas: eran 39 las que se pagaban, pero el número de artilleros era inferior, sólo 25. Las compañías de la milicia de la tierra dieron el siguiente resultado:

-batallón de la villa y del arrabal de la Marina: 270 hombres.

-compañía de milicia del cuartón de Santa Eulalia: 526 hombres.

-compañía de milicia del cuartón de Balansat: 300 hombres.

-compañía de milicia del cuartón de Portmany: 464 hombres.

-compañía de milicia del cuartón de las Salinas: 300 hombres.

-compañía de milicia del cuartón del llano de la villa: 247 hombres.

Total: 2.412 hombres.

La munición y el armamento hallados fueron los siguientes: 300 quintales de pólvora; 8.000 balas de hierro de diversos calibres; 90 quintales de plomo; 3 quintales de balas para mosquete y arcabuz; 93 quintales de cuerda; 150 mosquetes; 200 arneses completos (peto y espaldar) y 40 morriones. El gobernador demandaba: 200 quintales de cuerda; 100 quintales de balas de mosquete; 200 picas; 100 mosquetes; 100 arcabuces; 50 partesanas; 150 espadas; 25 pares de pistolas y 400 quintales de bizcocho -se quejaba de que los jurados no tenían prevenidos los 1.000 quintales de bizcocho de reserva en la guarnición tal y como prescribían las Ordenanzas. Artillería había 47 piezas, pero algunas necesitan arreglo en el montaje ${ }^{64}$.

En 1684, el gobernador J. Bayarte, al no contar con recibir ayuda ni de Valencia ni de Mallorca, pasó muestra general de los soldados de la guarnición y de la milicia de la isla, "de los quales, si llega la ocasión, se quedarán muchos por las montañas, sin entrar dentro de la plaça por no ser fácil conseguir con ellos que bengan". Le faltaban ciento cincuenta soldados para completar la dotación de infantería de la guarnición -190 plazas en teoría-, y los ciento cinco que tenía "se hallan unos muy biexos, otros enfermos, y todos desnudos muertos de [h]ambre padeciendo de necesidad con la dilación que ha tenido las asistencias desta plaça..."; de éstos, una tercera parte los daba por inútiles. La compañía de caballería, por entonces sólo treinta caballos, la mayoría los tenía muertos o fuera de servicio, por ser animales empleados en las labores del campo. El obispo de Tarragona debía mantener ocho caballos efectivos, habiendo sólo siete

${ }^{64}$ ACA, CA, Leg. 1.037, gobernador de Ibiza a la regente, 16-IV y 6-V-1666. 
entonces y de mala calidad, como se ha señalado, con un salario efectivo de veinte reales de plata al año; el arcediano de San Fructuoso, conseñor de la isla, tenía la obligación de mantener dos caballos, pero tan mal pagados como los anteriores, de modo que nadie quería servir; por último, la isla debía sufragar tres caballos y el resto el rey. De artilleros había treinta y dos al sueldo del rey. La compañía de Milicia del batallón de la villa de Ibiza contaba con 94 hombres, "entre los quales muchos viexos inútiles para las ocasiones de qualquier invasión"; la compañía del arrabal de la Marina tenía 160 hombres; la del cuartón de Santa Eulalia eran 627 hombres de buena calidad; la del cuartón de Balanzat eran 360 hombres; la del cuartón de Portmany contaba con 569 hombres; la del cuartón de las Salinas eran 206 hombres y del llano de la villa otros 250. En total, sumaban 167 soldados y otros 2.666 de las milicias. Como vemos, cifras que apenas han variado con respecto a las de $1666^{65}$. Sólo la mayor calidad de la fortificación ibicenca y de su artillería permitía un mínimo respiro a sus habitantes y a sus atribulados gobernadores.

En Menorca, el rey tenía una compañía de infantería de guarnición en Ciudadela, otra en Mahón, una compañía de caballería y dos escuadras de artillería. Pero la gran particularidad era que el alcaide del castillo de San Felipe de Mahón no dependía del gobernador de Menorca, radicado en Ciudadela; de hecho, los envíos de dinero para mantener ambas guarniciones se hacían por separado. En 1647, en plena Guerra de Cataluña, cuando desde las islas se debía dar apoyo a los ejércitos reales empeñados en la recuperación del Principado, el gobernador Josep de Rocabertí insistía en "los hodios que entre los naturales [h] ay causados de los continuos pleytos que estas universidades tienen, que pueden redundar en muy grande deservicio de V. Mag. si viniere, como amenaça el enemigo, a invadirla..." ${ }^{166}$. Según el gobernador J. Pardo, hacia 1671 en toda la isla, continuaba el virrey, habría 150 caballos útiles para servir y apenas 3.000 hombres de armas. El gobernador señalaba que Ciudadela tenía 561 hombres de armas y, por el perímetro de sus defensas, necesitaba tres veces dicha cantidad, de suerte que había que enviarles los de Mahón y de Alayor (663 hombres), porque de los de Mercadal y Ferreríes (325 hombres), trescientos se habían de enviar al castillo de Fornells. Pero los habitantes de Mahón se estimaban más defender su propia fortificación, que no refugiarse en la de Ciudadela con sus

\footnotetext{
${ }^{65}$ ACA, CA, Leg. 1.038, cartas del gobernador de Ibiza, J. Bayarte, al C.A., 4 y 20-IX-1684. ACA, CA, Leg. 1.038, gobernador de Ibiza al presidente del C.A., 5-II-1685; consultas del C.A., 23-II y 6-III-1685.

${ }^{66}$ ACA, CA, Leg. 1.022, J. Rocabertí a Felipe IV, 15-IV-1647.
} 
familias ${ }^{67}$. Tales cifras se mantuvieron en el resto de la centuria alarmando, como en 1693, ante el riesgo de un ataque de la armada francesa, al gobernador de turno, como V. Suau, quien en 1694 se sorprendió de "La poca providencia que hay en esta isla de lo que requiere la prevención de la defensa de un sitio, y la poca gente que hay en ella para oponerse al desembarco de los enemigos, como puede suceder por diferentes playas y calas que [h]ay por acá sin defensa alguna. La guarnición de Ciudadela, pagada por el rey, consistía en dos compañías, de infantería y caballería, pero "...es gente del pays sin disciplina militar, son propiamente milicias pues aunque gozan sueldo y están matriculados en los oficios de veeduría y contaduría no gozan de pan de munición, como lo gozan los del castillo de San Phelipe y Fornells, ni de todos los fueros militares, siendo assí que tienen más trabajo que los demás referidos". Consideraba que las milicias de la isla, que formaban dos batallones, uno en Ciudadela y su distrito, y otro de la parte foránea, necesitaban de oficiales reformados que pudieran imbuirles espíritu y disciplina militar y que los condujesen a los parajes más aptos para prevenir una invasión. Una realidad que se mantendría a inicios de la siguiente centuria ${ }^{68}$.

\section{CONCLUSIONES}

En la Monarquía Hispánica del siglo XVII, los problemas de reclutamiento de tropas eran tan agudos que las autoridades no tuvieron más elección que variar los sistemas de reclutamiento buscando las fórmulas más adecuadas por efectivas. Una solución podía ser la introducción de un plan general de milicias para servir en el Ejército Real, es decir, la conscripción obligatoria. De manera que se utilizó una fórmula de servicio militar sólo apto para la defensa local, la milicia territorial, para nutrir de nuevos reclutas las filas del Ejército Real. Como ha demostrado José Contreras, la fórmula fue un éxito en el caso de Castilla, pues los tercios provinciales acabaron por convertirse en la columna vertebral de las tropas de origen hispano que sirvieron en los frentes peninsulares a lo largo de la segunda mitad del siglo XVII.

${ }^{67}$ ACA, CA, Leg. 1.022, virrey de Mallorca a la regente, 2-XII-1672. ACA, CA, Leg. 1.022, virrey al rey, 17-III-1677; gobernador Pardo al rey, 10-VII-1678.

${ }^{68}$ ACA, CA, Leg. 1.023, consulta del C.A., 20-VI-1693; gobernador al Protonotario, 27-VII1693; consulta del C.A., 6-X-1693; gobernador a Protonotario, 22-IV-1694; gobernador Suau Veintimilla al rey, 30-VI-1694. 
En el caso de los reinos de la Corona de Aragón, la Monarquía tuvo la necesidad de conseguir un cierto apoyo militar extra, puesto que sus deficiencias defensivas, especialmente en el caso del frente catalán, fueron muy evidentes a lo largo de los cuatro conflictos tenidos con la Francia de Luis XIV durante el reinado de Carlos II. Todos los reinos de la Corona de Aragón no sólo levaron, pagaron y reclutaron sustitutos para mantener sus respectivos tercios en el número de plazas que habían prometido al rey, sino que, además, los enviaron a servir a Cataluña, Navarra o Extremadura, es decir, fuera de sus territorios -salvo los catalanes cuando había guerra en su frontera, obviamente. Era esta una situación que, siendo claramente inconstitucional, fue tolerada sistemáticamente por todos ellos, y, a pesar de todo, los ataques marítimos franceses en el caso valenciano o mallorquín, o desbordando la frontera catalana en el caso aragonés, obligó a sus autoridades a aceptar la creación de milicias generales en sus territorios para la autodefensa. Como hemos visto en el caso aragonés, el más desarrollado por nosotros en este trabajo, las autoridades del citado Reino estuvieron muy pendientes para impedir que dicho servicio, que apenas se esbozó en la práctica, acabase dando pie a nuevos envíos de tropas fuera de las fronteras del Reino. En cualquier caso, la lógica militar que, por ejemplo, podía demandar frenar a los franceses en Cataluña antes que asaltasen Aragón, chocó a menudo con los intereses particulares de los reinos en cuestión, intereses que podían ser, además, muy diversos, pero no dejaban de ser muy conscientes que, en la España de Carlos II la única fórmula para dejar de realizar algunas de las demandas de la Monarquía era no discutir por qué, pero sí cuándo, cómo, de qué manera y durante cuánto tiempo debía realizarse tal o cuál petición. 